\title{
Sensitive Analysis of $\alpha$-Synuclein by Nonlinear Laser Wave Mixing Coupled with Capillary Electrophoresis
}

\author{
Manna F. Iwabuchia, Marcel M. Hetu ${ }^{\mathrm{b}}$, and William G. Tong ${ }^{\text {c* }}$ \\ Department of Chemistry and Biochemistry, San Diego State University \\ San Diego, CA , USA, 92182 \\ (619) 594-5929, william.tong@sdsu.edu
}

\begin{abstract}
a: Department of Chemistry and Biochemistry, San Diego State University
San Diego, CA, USA, 92182

manna.f.iwabuchi@gmail.com

b: Department of Chemistry and Biochemistry, San Diego State University

San Diego, CA, USA, 92182

marcel.hetu@cox.net

$\mathrm{C}^{*}$ : Corresponding Author

Department of Chemistry and Biochemistry, San Diego State University

San Diego, CA, USA, 92182

william.tong@sdsu.edu
\end{abstract}

Subject Category: Protein analysis and Electrophoresis 


\section{Abstract}

Multi-photon nonlinear laser wave-mixing spectroscopy is a novel absorption-based technique that offers excellent detection sensitivity for biomedical applications including early diagnosis and investigation of neurodegenerative diseases. $\alpha$-Synuclein is linked to Parkinson's disease (PD), and characterization of its oligomers and quantification of the protein may contribute to understanding PD. The laser wave-mixing signal has a quadratic dependence on analyte concentration, and hence, the technique is effective in monitoring small changes in concentration within biofluids. A wide variety of labels can be employed for laser wave-mixing detection due to its ability to detect both chromophores and fluorophores. In this paper, two fluorophores and a chromophore are studied and used as labels for the detection of $\alpha$-synuclein. Wave mixing detection limits of PD-related protein conjugated with fluorescein isothiocyanate, QSY 35 acetic acid, succinimidyl ester and Chromeo P503 are determined to be $1.4 \times 10^{-13} \mathrm{M}, 1.4 \times 10^{-10} \mathrm{M}$, and $1.9 \times 10^{-13} \mathrm{M}$, respectively. Based on the laser probe volume used, the corresponding mass detection limits are determined to be $1.1 \times 10^{-23} \mathrm{~mol}, 1.1 \times 10^{-20} \mathrm{~mol}$, and $1.5 \times 10^{-23} \mathrm{~mol}$, respectively. This study also presents molecular-based separation and quantification of $\alpha$ synuclein by laser wave mixing coupled with capillary electrophoresis.

Keywords: ultrasensitive nonlinear spectroscopy; electrophoresis; $\alpha-$ synuclein; Parkinson's

Abbreviation used: CSF, cerebrospinal fluid; CGE, capillary gel electrophoresis; CZE, capillary zone electrophoresis 


\section{Introduction}

\section{$1.1 \alpha-S y n u c l e i n$ as Candidate Biomarker for Parkinson's Disease}

Parkinson's disease is the second most predominant neurodegenerative disease in the U.S., afflicting 1-2 \% of the population aged 65 and over [1]. The disease is clinically characterized by the progressive dysfunction of several motor and non-motor neurological functions [2]. A series of studies showed that intercellular accumulation of Lewy bodies (LB), the hallmark of PD, appears 6 years or more before the symptoms emerge [3]. Thus, accurate quantification and detection of LB-related proteins, such as $\alpha$-synuclein [4], at a sensitive level is key to pave the way to understanding PD.

a-Synuclein is a $14 \mathrm{kDa}, 140$-residue neural protein highly expressed in central neurons and localized in presynaptic terminals [5]. The protein is a major component of LBs (aggregated proteins), the hallmark pathology of PD and those with dementia $[6,7]$. The mechanisms and inclusion of $\alpha$-synuclein in LBs do not explain the pathogenesis of the neurodegenerative disease, and it remains unclear whether LBs are a cause or a symptom [8].

Parkinson's disease was believed to be genetically inherited, since several families with PD history were found to possess a mutation of $\alpha$-synuclein. Based on this finding, numerous studies developed a hypothesis that both point mutations and multiplications in the $\alpha$-synuclein gene cause PD [9]. Lee and Trojanowski suggested that $\beta$-sheet structure of $\alpha$-synuclein, readily oligomerized and aggregated, is induced by both pathogenic mutations and elevated levels of $\alpha$ synuclein [10]. The aggregation of the protein $(5-25 \mu \mathrm{m})$ [11] is accelerated by 
various types of post-translational modification, such as Ser-129 phosphorylation, calpain-mediated cleavage, O-glycosylation, tyrosine nitration, methionine oxidation and C-terminal truncation [12].

Currently, the toxicity of the oligomerized and protofibril intermediate $\alpha$ synuclein is widely accepted $[13,14]$. In addition to the LB hallmark, destruction of dopaminergic neurons are observed in early stages of PD [15-17]. Conway et al. reported that the formation of oligomerized $\alpha$-synuclein can be accelerated by dopamine, although the mechanism remains unclear [18]. Südhof et al. suggested that the formation of soluble $\mathrm{N}$-ethylmaleimide sensitive factor attachment protein receptor (SNARE) complex, critical to the vesicle fusion leading to dopamine release, is promoted by $\alpha$-synuclein binding to a vesicular SNARE protein, synaptobrevin-2 [19]. On the other hand, Choi et al. reported that large $\alpha$-synuclein oligomers inhibit neuronal SNARE-meditated vesicle lipid mixing [7].

In addition to cerebrospinal fluid (CSF) analysis, levels of $\alpha$-synuclein in blood samples have been tested in order to develop less invasive diagnostic methods for PD. Kasuga et al. reviewed studies of blood samples from a control group and from PD patients to compare $\alpha$-synuclein levels. They concluded that, due to the lack of a sensitive detection and quantification method that can differentiate $\alpha$-synuclein species (truncated, phosphorylated, monomeric and oligomeric forms) [20], the levels of PD-related proteins are still unclear. 


\subsection{Current Detection Method for a-Synuclein}

A sensitive detection method is needed in order to develop an early diagnostic tool for Parkinson's disease. Currently, enzyme-linked immunosorbent assay (ELISA) is commonly used for detecting monomeric and oligomeric forms of a-synuclein in CSF and serum; however, ELISA is usually designed specifically for analyzing a single analyte and cannot be coupled to a separation device. ELISA is a time-consuming assay that requires multiple steps to detect and quantify a target protein. The ELISA well is coated with a target protein-specific antibody that binds to the protein when a sample is introduced. The enzyme-linked antibody may react with an unbound site of the protein. Free antibodies that do not react with the protein are removed by washing. Additionally, ELISA yields inconsistent results [21-26] for control groups due to background absorption and crossreactivity interference [27]. The assay may yield false-positive results, i.e., a signal may not be generated by $\alpha$-synuclein antigen-antibody reaction or specify monomeric and oligomeric forms.

Our wave-mixing detection sensitivity is orders of magnitude better than those of conventional absorption techniques, and comparable or better than those of ELISA and fluorescence methods. Laser wave mixing also provides shorter analysis times and better chemical specificity without the use of expensive antibody. Sodium dodecyl sulfate-capillary gel electrophoresis (CGE) or capillary zone electrophoresis (CZE) can distinguish monomeric and oligomeric forms. Unlike laser-induced fluorescence (LIF), laser wave mixing can detect both fluorophores and chromophores. Moreover, the wave-mixing signal is a coherent 
laser-like beam and it can be detected conveniently with high collection efficiency and high $\mathrm{S} / \mathrm{N}$.

\subsection{Laser Wave Mixing for $\alpha-S y n u c l e i n$ Detection}

The wave-mixing signal exhibits excellent properties including quadratic dependence on analyte extinction coefficient, i.e., concentration, and cubic dependence on intensity of the excitation laser source. The wave-mixing signal can be described with the following equation [28].

$$
I_{3}=\left(\frac{b}{8 \pi}\right)^{2} l_{1}^{2} I_{2} \frac{\lambda}{\sin ^{4}(\theta / 2)}\left(\frac{d n}{d T}\right)^{2} \frac{a^{2}}{\kappa^{2}}
$$

The intensity of the wave-mixing signal $\left(I_{3}\right)$ produced by the probe and pump beams depends on the cross section of the path length of a laser beam (b), intensities of excitation laser source $\left(I_{1}\right.$ and $\left.I_{2}\right)$, the wavelength of the laser source $(\lambda)$, the angle between the probe and pump beams $(\theta)$, a derivative of the refractive index with respect to solvent temperature change $(d n / d T)$, the extinction coefficient $(\alpha)$, and thermal conductivity $(k)$. Equation 1 indicates that the wave-mixing signal has a quadratic dependence on analyte concentration, and hence, it allows more effective measurement of small changes in analyte concentration as compared to conventional absorption and fluorescence methods. Both sensitivity and selectivity levels are enhanced when wave mixing is coupled with CE. Excellent separation resolutions, zeptomole-level sensitivity, fast analysis, and small sample requirements $[29,30]$ are some of the advantages of wave-mixing CE. Taking advantage of these unique features of laser wave mixing, concentration detection limits of PD-related protein conjugated with fluorescein isothiocyanate, QSY 35 
acetic acid, succinimidyl ester and Chromeo P503 are determined to be $1.4 \times 10^{-}$ ${ }^{13} \mathrm{M}, 1.4 \times 10^{-10} \mathrm{M}$, and $1.9 \times 10^{-13} \mathrm{M}$. Based on the small probe volume $(79 \mathrm{pL})$ used, corresponding mass detection limits of $1.1 \times 10^{-23} \mathrm{~mol}, 1.1 \times 10^{-20} \mathrm{~mol}$, and $1.5 \times 10^{-23} \mathrm{~mol}$, are determined.

\section{Materials and Methods}

\subsection{Forward-Scattering Laser Wave-Mixing Experimental Setup}

Figure 1 shows a schematic diagram of forward-scattering wave-mixing optical setup interfaced to a CE system. A continuous-wave $488 \mathrm{~nm}$ blue laser with adjustable power tuned to $40 \mathrm{~mW}$ (Coherent, Santa Clara, CA) and a $50 \mathrm{~mW}$ $473 \mathrm{~nm}$ diode laser ( $\mathrm{CNI}$, Changchun, China) are used for visible-wavelength wave-mixing detection. A $266 \mathrm{~nm}$ UV pulsed laser (CNI, Changchun, China, 20 $\mathrm{mW}, 7 \mathrm{kHz}$ ) is used for UV wave-mixing detection of $\alpha$-synuclein. The laser output is first split by a beam splitter (R:T 30:70) to create two input beams. The weaker (reflected) input beam is modulated by an optical chopper (Stanford Research Systems, Sunnyvale, CA, SR541) at $200 \mathrm{~Hz}$. In Figure 1, the solid line and the dotted line represent unmodulated and modulated beam, respectively. The two input laser beams travel the same distances and then cross at an angle of $0.95^{\circ}$ (488 $\mathrm{nm}$ laser) or $1.5^{\circ}$ (473 nm laser and $266 \mathrm{~nm}$ laser). The excitation lasers yield beam diameters of $1.70 \mathrm{~mm}(488 \mathrm{~nm}), 1.20 \mathrm{~mm}(473 \mathrm{~nm})$ and $1.10 \mathrm{~mm}(266 \mathrm{~nm})$, and probe volumes of $78 \mathrm{pL}(488 \mathrm{~nm}), 58 \mathrm{pL}(473 \mathrm{~nm})$, and $55 \mathrm{pL}(266 \mathrm{~nm})$. A 75 $\mu \mathrm{m}$ i.d. fused-silica capillary (Molex, Lisle, IL) is used as the analyte cell into which the analyte is loaded by electrokinetic injection. A small portion of the capillary coating is removed by a butane flame so that the input laser beams can propagate 
through the capillary analyte cell. The wave-mixing signal is collected by a simple photodetector (Thorlabs, Newton, NJ, PDA25K). The optical chopper, the photodetector and the computer are interfaced to a lock-in amplifier (Stanford Research Systems, Sunnyvale, CA, SR810 DSP)

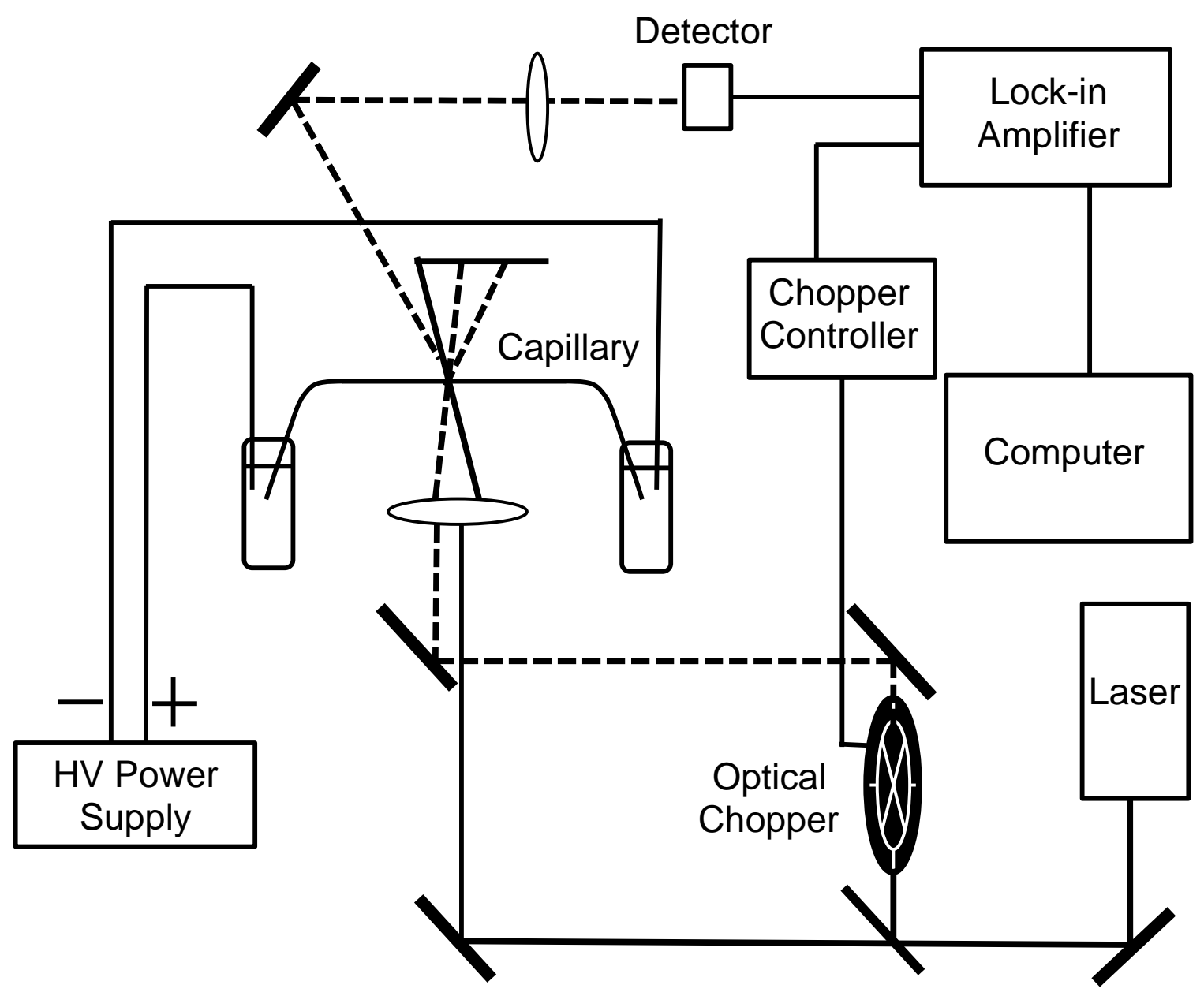

Fig. 1. Forward-scattering wave-mixing experimental setup coupled with capillary electrophoresis for $\alpha$-synuclein detection. 


\subsection{Chemicals}

Solutions used for this study are prepared with distilled water from a compact water distillation system. Borax, Tris base, sodium dodecyl sulfate (SDS), sodium bicarbonate and poly (ethylene glycol) (PEG, 10,000) are purchased from Sigma-Aldrich. Fluorescein isothiocyanate (FITC), CHES, hydrochloric acid, sodium hydroxide, unstained protein ladder, N,N-Dimethylformamide (DMF) and dialysis tubing (MWco 12-14 kDa) are purchased from Thermo Fisher Scientific. The chromophore label, QSY 35 acetic acid, succinimidyl ester is obtained from Life Technologies. The capillary is coated with Ultratrol LN (Target Discovery) by flowing through the solution for 2 to 5 minutes, and a sieving matrix is prepared by flowing PEG in the sample cell. Recombinant $\alpha$-synuclein, a DNA sequence encoding the human $\alpha$-synuclein sequence, is expressed in E. coli (rPeptide). Fluorophore protein label, Chromeo ${ }^{\mathrm{TM}} \mathrm{P} 503$, is purchased from Active Motif.

\subsection{Fluorescein isothiocyanate-conjugated protein}

Sodium borate reaction buffer $(50 \mathrm{mM}, \mathrm{pH}$ 8.6) is prepared by dissolving borax in distilled water, and $\mathrm{pH}$ is adjusted by using $1.0 \mathrm{M} \mathrm{HCl}$. Proteins are dissolved in the buffer at $2.0-2.2 \mathrm{mg} / \mathrm{mL}$. FITC, a fluorophore label, is dissolved in DMF $(10-20 \mathrm{mg} / \mathrm{mL})$ to react with proteins. The mixture of FITC and protein(s) is allowed to proceed for 1 hour in the dark. Dialysis is performed to remove free FITC using regenerated cellulose dialysis tubing (MWco $12,000 \mathrm{kDa}-14,000 \mathrm{kDa}$ ) and buffer exchange is performed 
simultaneously to prepare FITC-conjugated protein in Tris-CHES buffer (25 $\mathrm{mM})$ with SDS (0.1\%).

Molecular weight and migration time calibration curves are generated by running FITC-conjugated protein ladder that includes seven proteins: lysozyme (14.4 kDa), $\beta$-lactoglobulin (18.4 kDa), REase Bsp98I (25.0 kDa), lactate dehydrogenase $(35.0 \mathrm{kDa})$, ovalbumin $(45.0 \mathrm{kDa})$, bovine serum albumin $(66.2 \mathrm{kDa})$, and $\beta$-galactosidase $(116 \mathrm{kDa})$. The unstained proteins are present in the solution at various concentration levels $(0.10-0.20$ $\mathrm{mg} / \mathrm{mL})$. The stock solution $(150 \mu \mathrm{L})$ is aliquoted and dialyzed into conjugation buffer for the protein ladder to react with FITC using the previously stated protocol.

\subsection{QSY 35 Acetic Acid, Succinimidyl Ester-Conjugated a-Synuclein}

Lyophilized $\alpha$-synuclein is resuspended in $450 \mu \mathrm{L}$ water to obtain $2.2 \mathrm{mg} / \mathrm{mL}$ protein in Tris- $\mathrm{HCl}$ and $\mathrm{NaCl}$ buffer ( $\mathrm{pH}$ 7.4). The buffer is replaced with sodium carbonate-sodium bicarbonate reaction buffer $(100 \mathrm{mM}, \mathrm{pH}$ 8.3) using regenerated cellulose dialysis tubing. a-Synuclein is reacted with QSY 35 in DMF $(20 \mathrm{mg} / \mathrm{mL})$ for 1 hour in the dark (1:20). Excess dye is removed by dialysis while carbonate buffer is changed to Tris-CHES (100 mM) with $0.1 \%$ SDS.

\subsection{Chromeo P503-Conjugated Protein}

Using an aliquot of $2.2 \mathrm{mg} / \mathrm{mL} \alpha$-Synuclein $(100 \mu \mathrm{L})$ described above, Chromeo P503 is dissolved in DMF $(5.0 \mathrm{mg} / \mathrm{mL})$ and added to the aliquot 
dropwise to obtain a 1:4 ratio or greater. The solution is gently mixed for 30 minutes until the original color of the dye (blue) changes to red.

\subsection{Custom-Built Capillary Electrophoresis}

Background electrolyte Tris-CHES is prepared by dissolving Tris $(1.04 \mathrm{~g})$ and CHES $(0.607 \mathrm{~g})$ in distilled water $(100 \mathrm{~mL})$ and adjusting $\mathrm{pH}$ to 9.0 . Sieving matrix is prepared by dissolving PEG (3\%) into Tris-CHES buffer $(100 \mathrm{mM})$ with $0.1 \%$ high purity electrophoresis-grade sodium dodecyl sulfate (SDS). All the capillary electrophoresis (CE) runs are performed by a custom-built CE system, which uses a fused-silica capillary and a high voltage power supply (Glassman High Voltage, High Bridge, NJ) that is connected to platinum wires. Voltage is controlled by a custom-built voltage controller. Plastic reservoirs containing running buffer/samples are placed at each end of the capillary.

\subsection{UV-Visible Absorption Spectra}

UV-visible absorption spectra are obtained by a UV-visible spectrophotometer (Agilent, Santa Clara, CA, 8453) using $1 \mathrm{~cm}$ Quartz cuvettes. Absorption spectra are blanked using an appropriate solvent before measuring each analyte. 


\section{Results and Discussion}

\subsection{UV-Visible Analysis of $\alpha$-Synuclein and Amine-Reactive Labels}

Since laser wave mixing is an absorption-based technique, labels are not required when the analyte absorbs the excitation source. Measuring absorption spectra of analytes allows one to choose an appropriate laser to use in a laser wave-mixing CE setup. Figure 2 shows UV-visible absorption spectra of $\alpha$ synuclein and labels used in this study. a-Synuclein absorbs UV wavelengths due to aromatic amino acid residues, such as tyrosine and phenylalanine; however, the protein optical absorption is weak at the $266 \mathrm{~nm}$ laser excitation wavelength. Nevertheless, laser wave mixing allows label-free detection of the native protein with molar detection limit of $410 \mu \mathrm{M}$ and mass detection limit of $24 \mathrm{fmol}$. Detection sensitivity can be significantly enhanced, by conjugating the protein with a label to increase the absorption coefficient. Since every protein possesses N-terminus, and lysine $(\mathrm{K})$ is relatively abundant, amine-reactive dyes are widely used for protein labeling. According to the amino acid sequence of $\alpha$-synuclein, 16 labeling sites are available for conjugation as shown in Figure 3; however, due to steric hindrances and the protein conformation, not all the sites are accessible. 


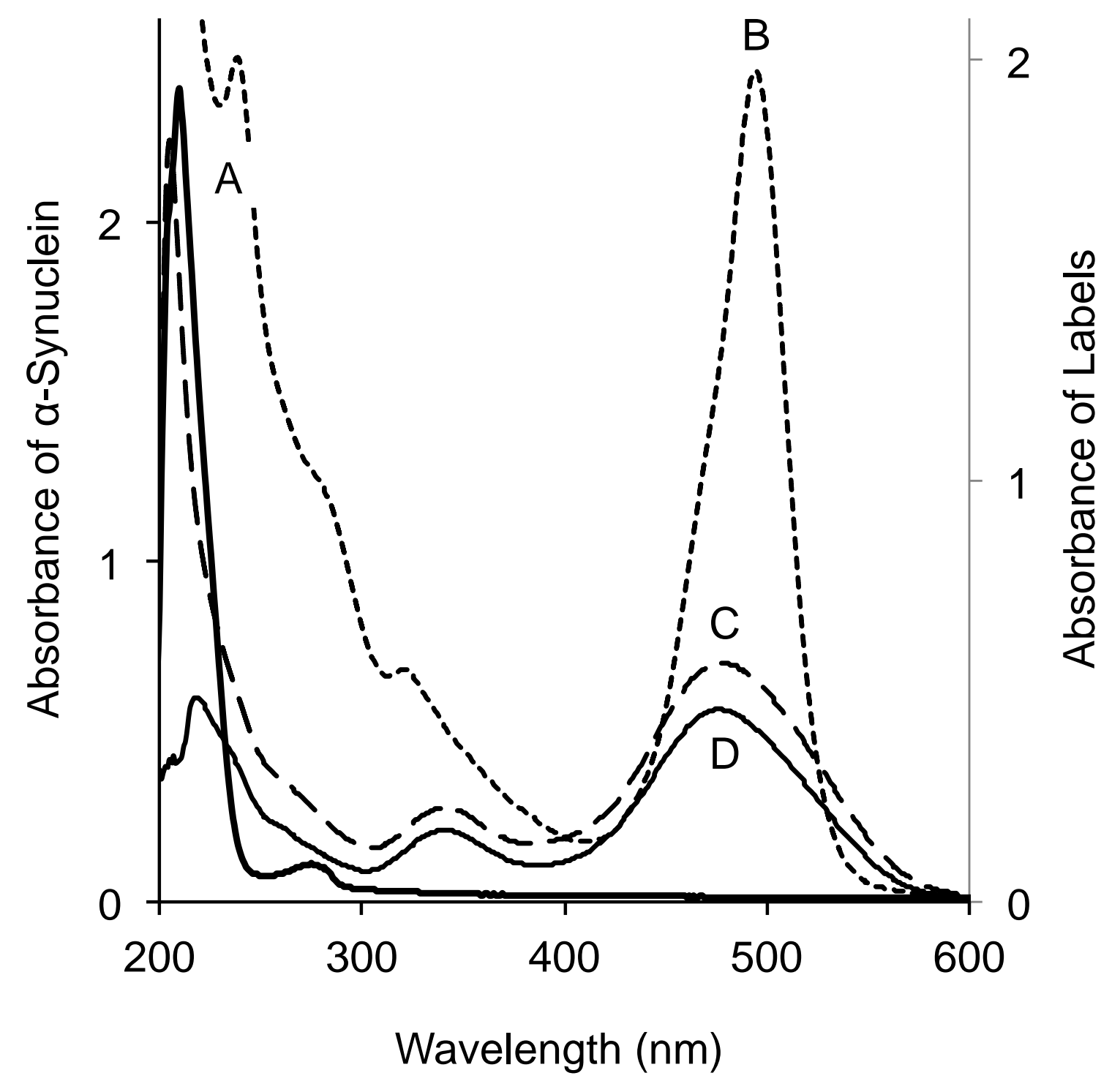

Fig. 2. UV-visible absorption spectra of (A) $\alpha$-synuclein $\left(1.5 \times 10^{-5} \mathrm{M}\right)$, (B) FITCconjugated $\alpha$-synuclein $\left(7.0 \times 10^{-6} \mathrm{M}\right),(\mathrm{C})$ QSY 35-conjugated $\alpha$-synuclein $(7.0 \times$ $\left.10^{-6} \mathrm{M}\right)$, and (D) Chromeo P503-conjugated $\alpha$-synuclein $\left(5.6 \times 10^{-6} \mathrm{M}\right)$. A, C and D are in carbonate buffer $(100 \mathrm{mM}, \mathrm{pH} 8.3)$, and $B$ is in borate buffer $(50 \mathrm{mM}, \mathrm{pH}$ 8.6). 


\begin{tabular}{|rrr|}
\hline 10 & 20 & 30 \\
MDVFMKGLSK & AKEGVVAAAE & KTKQGVAEAA \\
& & \\
40 & 50 & 60 \\
GKTKEGVLYV & GSKTKEGVVH & GVATVAEKTK \\
& & \\
70 & 80 & 90 \\
EQVTNVGGAV & VTGVTAVAQK & TVEGAGSIAA \\
& & 120 \\
100 & 110 & \\
ATGFVKKDQL & GKNEEGAPQE & GILEDMPVDP \\
& & \\
130 & 140 & \\
DNEAYEMPSE & EGYQDYEPEA & \\
& & \\
& &
\end{tabular}

Fig. 3. Amino acid sequence of $\alpha$-synuclein. Lysine $(\mathrm{K})$ and $\mathrm{N}$-terminus are amine reactive sites. 
FITC is a widely used amine-reactive fluorophore with excitation $\lambda_{\max }$ at 495 $\mathrm{nm}$, an excitation coefficient of $70,000 \mathrm{M}^{-1} \mathrm{~cm}^{-1}$, and emission $\lambda_{\max }$ at $525 \mathrm{~nm}$. In this study, 20-mole excess FITC is reacted with the protein for 1 hour before dialysis. QSY 35 is a chromophore label that is used as an acceptor of fluorescence resonance energy transfer (FRET) applications [31]. Its maximum absorbance is at $475 \mathrm{~nm}$ with an extinction coefficient of $23,000 \mathrm{M}^{-1} \mathrm{~cm}^{-1}$ that is suitable for laser wave mixing with an excitation laser source of $488 \mathrm{~nm}$ or $473 \mathrm{~nm}$. Chromeo $^{\mathrm{TM}} 503$ displays maximum absorption at $503 \mathrm{~nm}$, and its labeling reaction time is only 30 minutes. The molecular structure of the fluorophore is unclear but Py-1 introduced by Wolfbeis appears to be an identical compound [32].

The unique features of Chromeo P503 as a fluorophore label is shown in Figure 4. Its absorption peak shifts from $603 \mathrm{~nm}$ to $503 \mathrm{~nm}$ after conjugation with protein, resulting a color shift from red to blue. Chromeo P503-conjugated protein analysis is faster since the reaction time is shorter, and it does not require dialysis when $488 \mathrm{~nm}$ laser is used as the excitation source. Extinction coefficient changes from $60,000 \mathrm{M}^{-1} \mathrm{~cm}^{-1}$ to $24,000 \mathrm{M}^{-1} \mathrm{~cm}^{-1}$ through the reaction when 4 molar excess label is introduced (manufacturer recommended ratio). There are more unconjugated labeling sites on the protein as compared to the other two labels with 1:20 (protein : label) reaction ratio. Increasing Chromeo P503 concentration for the reaction can easily enhance the extinction coefficient of the analyte. In addition, Chromeo forms a relatively stable molecule and its stock solution does not deteriorate, so it can be used for several months [33]. Moreover, the dye can 
be conjugated with a protein without changing the charge of the protein during the process in order to preserve its native form [34].

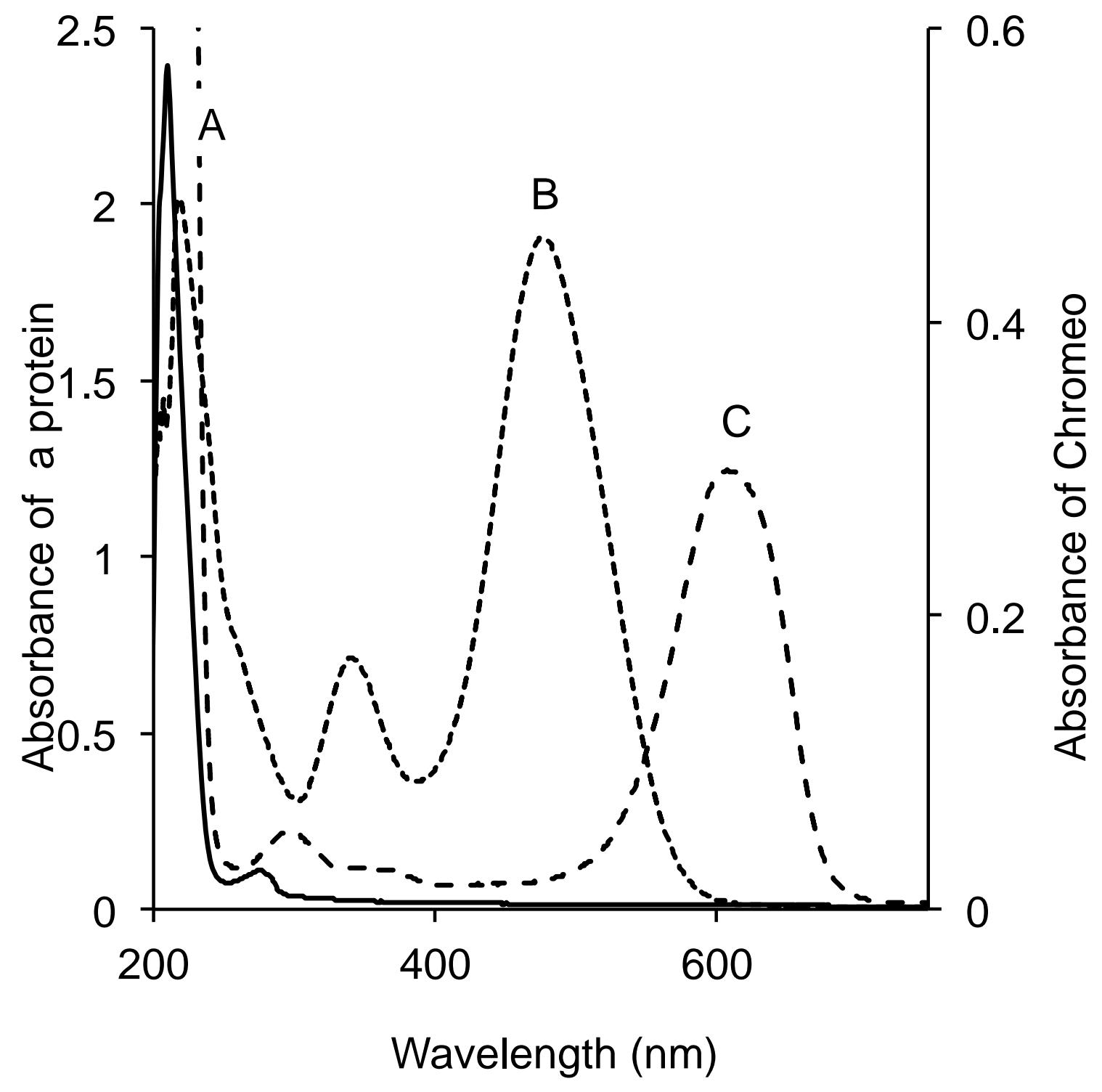

Fig. 4. Wavelength shift observed for Chromeo P503. Conjugation with a-synuclein shifts approximately $100 \mathrm{~nm}$. (A) a-synuclein (1.5 x 10-5 M), (B) Chromeo P503conjugated a-synuclein $\left(5.6 \times 10^{-6} \mathrm{M}\right)$, and $(\mathrm{C})$ Chromeo P503 $\left(6.4 \times 10^{-6} \mathrm{M}\right)$. All solutions are prepared in $100 \mathrm{mM}$ sodium carbonate-sodium bicarbonate buffer (pH 8.3). 


\section{2 a-Synuclein Molecular Weight Determination Using Sieving Capillary Electrophoresis}

Nonlinear wave mixing, interfaced to capillary gel electrophoresis (CGE), can identify monomer, oligomerized and fibril $\alpha$-synuclein in their native forms.

Detergents have the potential to breakdown physiological assemblies, thus they are not used while performing molecular weight-based separation. Figure 5 shows an electropherogram of molecular weight-based separation of $\alpha$-synuclein one can use to identify its oligomeric forms. Molecular weights of the analytes are obtained by running a standard FITC-conjugated protein ladder as shown in Figure 6 . The main peaks around $55.3 \mathrm{kDa}$ indicate that the most stable form of $\alpha$-synuclein is a tetramer with some dimeric (27-39 kDa) and higher oligomeric forms (approximately $100 \mathrm{kDa}$ ). The results obtained by this study closely match a study by Bartels et al., wherein the molecular weight of the protein is determined using scanning transmission electron microscopy (STEM) under non-denaturing conditions [35]. They validated their STEM results by sedimentation equilibrium analytical ultracentrifugation (SE-AUC), which is commonly used to establish the oligomeric state of native proteins independent of their conformation. In addition, Bartels et al. developed a non-denaturing method to purify native $\alpha$-synuclein from RBC, which can be applied to perform analysis with our analytical method [35]. Thus, CE-based laser wave mixing is capable of providing accurate analysis of the native protein conformation and has the potential to help understand the function of a-synuclein for Parkinson's disease. 


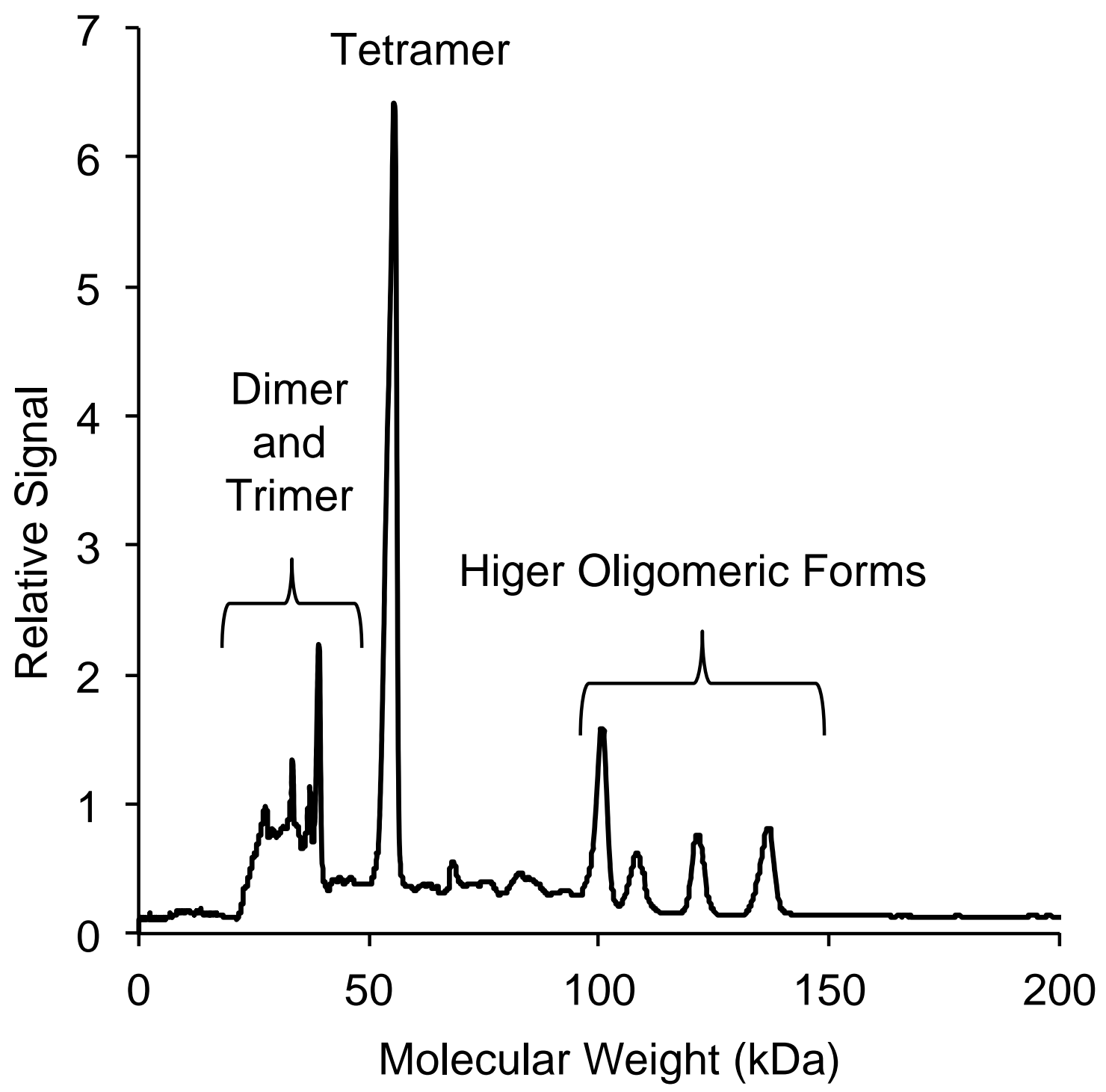

Fig. 5. Electropherograms of size-based separation of FITC-conjugated asynuclein $\left(1.4 \times 10^{-5} \mathrm{M}\right)$. The capillary $(75 \mu \mathrm{m}$ i.d., $50 \mathrm{~cm})$ is rinsed with $\mathrm{NaOH}(0.1$ $\mathrm{M})$, water and UltraTrol for 3 minutes followed by running buffer (3\% PEG, $100 \mathrm{mM}$ Tris-CHES, and $0.1 \%$ SDS). $15.0 \mathrm{kV}$ is applied for each CE run (reverse polarity). The sample is injected electrokinetically for 5 seconds. Wave-mixing signal detected by using a $50 \mathrm{~mW} 473 \mathrm{~nm}$ laser. 


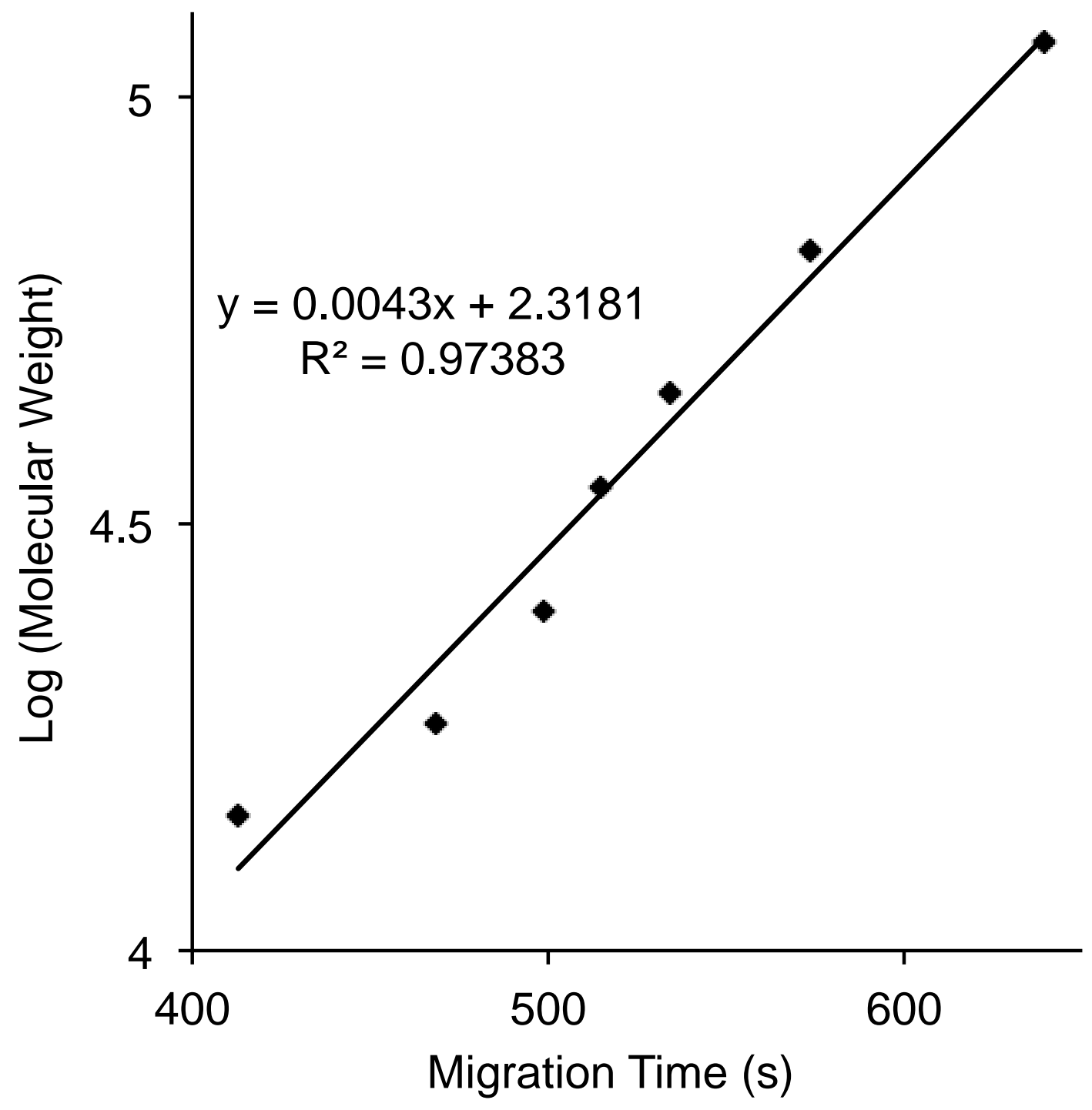

Fig. 6. Calibration curve created by standard protein ladder for sizing FITCconjugated $\alpha$-synuclein. Log of molecular weight versus migration has a linear dependence. 


\subsection{Pico- and Femto-Molar and Zepto-Mole Detection of $\alpha$-Synuclein}

Laser wave mixing, interfaced to $\mathrm{CE}$, yields excellent detection limits when using label-conjugated $\alpha$-synuclein. The three types of labels discussed earlier are used in this study. Figure 7, 8 and 9 show electropherograms of $\alpha$-synuclein conjugated with FITC, QSY 35 and Cheomeo P503. Each figure is obtained by running CE-based laser wave mixing (488 $\mathrm{nm}$ laser) with different concentration levels of labeled proteins. The protein is reacted with FITC and QSY 35 at a ratio of 1 to 20 , and Chromeo P503 at 1 to 4 , as recommended by the manufacturer for individual labels. Concentration detection limits of $1.4 \times 10^{-13} \mathrm{M}$ (FITC), $1.4 \times 10^{-10}$ M (QSY 35), and $1.4 \times 10^{-10} \mathrm{M}$ (Chromeo P503) are determined for conjugated $\mathrm{a}-$ synuclein as shown in Table 1. Based on the small probe volume used, mass detection limits of $1.1 \times 10^{-23} \mathrm{~mol}$ (FITC), $1.1 \times 10^{-20} \mathrm{~mol}$ (QSY 35), and $1.1 \times 10^{-20}$ mol (Chromeo P503) are determined for conjugated proteins. This is equivalent to detecting as few as 7 molecules (FITC-labeled) inside the probe volume. FITCconjugated protein has the highest extinction coefficient at $488 \mathrm{~nm}$, and it reaches the best detection limit by three orders of magnitude as compared to those for QSY 35 and Chromeo P503-conjugated a-synuclein. Migration time for the FITCconjugated protein is shorter than those of QSY 35 and Chromeo P503 conjugated-protein since higher voltage is applied to the system. 


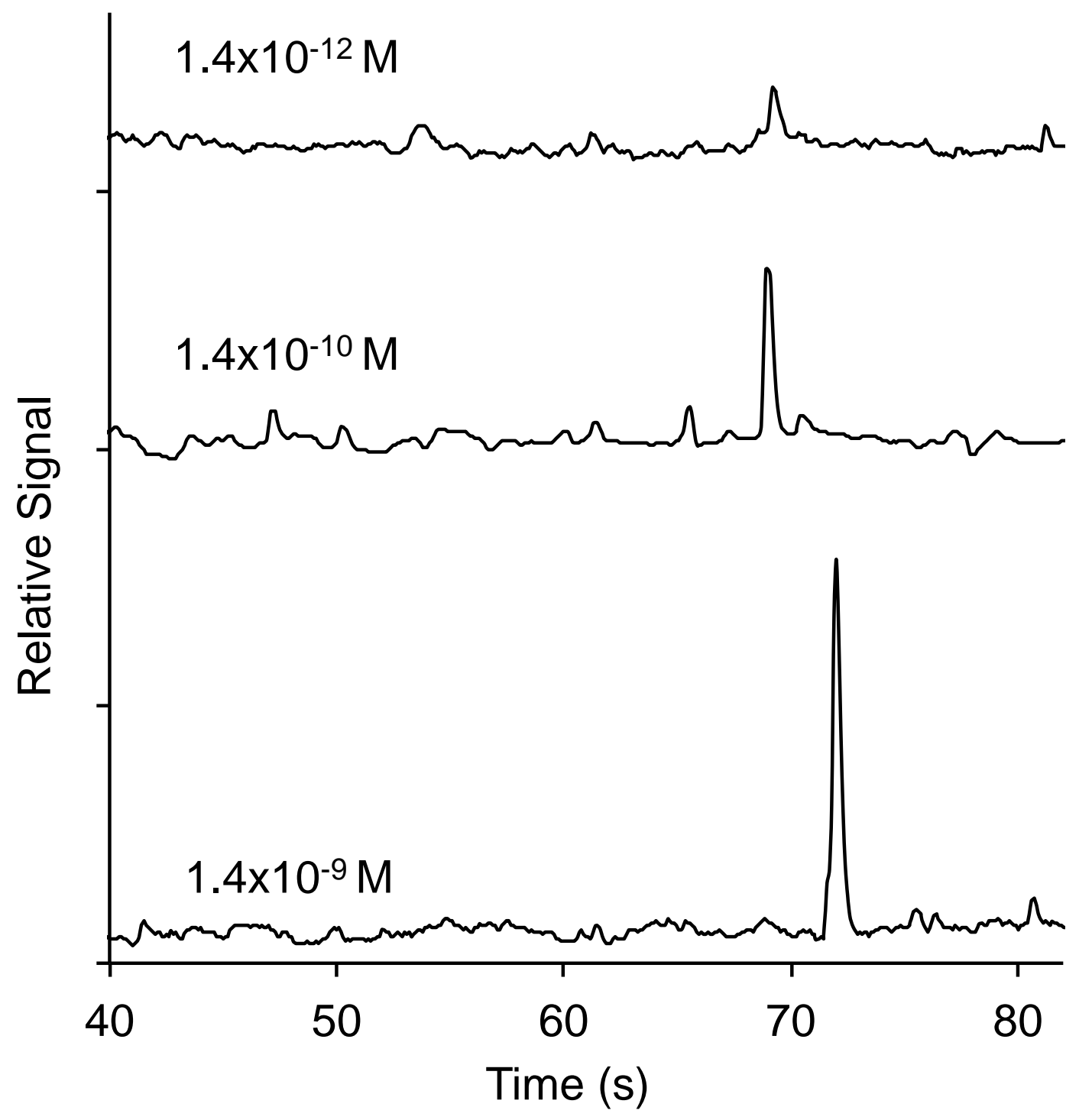

Fig. 7. Detection limit study of FITC-conjugated a-synuclein. Different concentrations, $1.4 \times 10^{-9} \mathrm{M}, 1.4 \times 10^{-10} \mathrm{M}$ and $1.4 \times 10^{-12} \mathrm{M}$, of the protein are detected by CE-based laser wave mixing using a $488 \mathrm{~nm}$ laser. Capillary is rinsed with $\mathrm{NaOH}(0.1 \mathrm{M})$, water, UltraTrol, and background electrolyte for 3 minutes. Capillary: $75 \mu \mathrm{m}$ i.d., $30 \mathrm{~cm}$ (15 cm effective length). $18.5 \mathrm{kV}$ is applied for each run (reverse polarity). The sample is injected electrokinetically for $20 \mathrm{~s}$. 

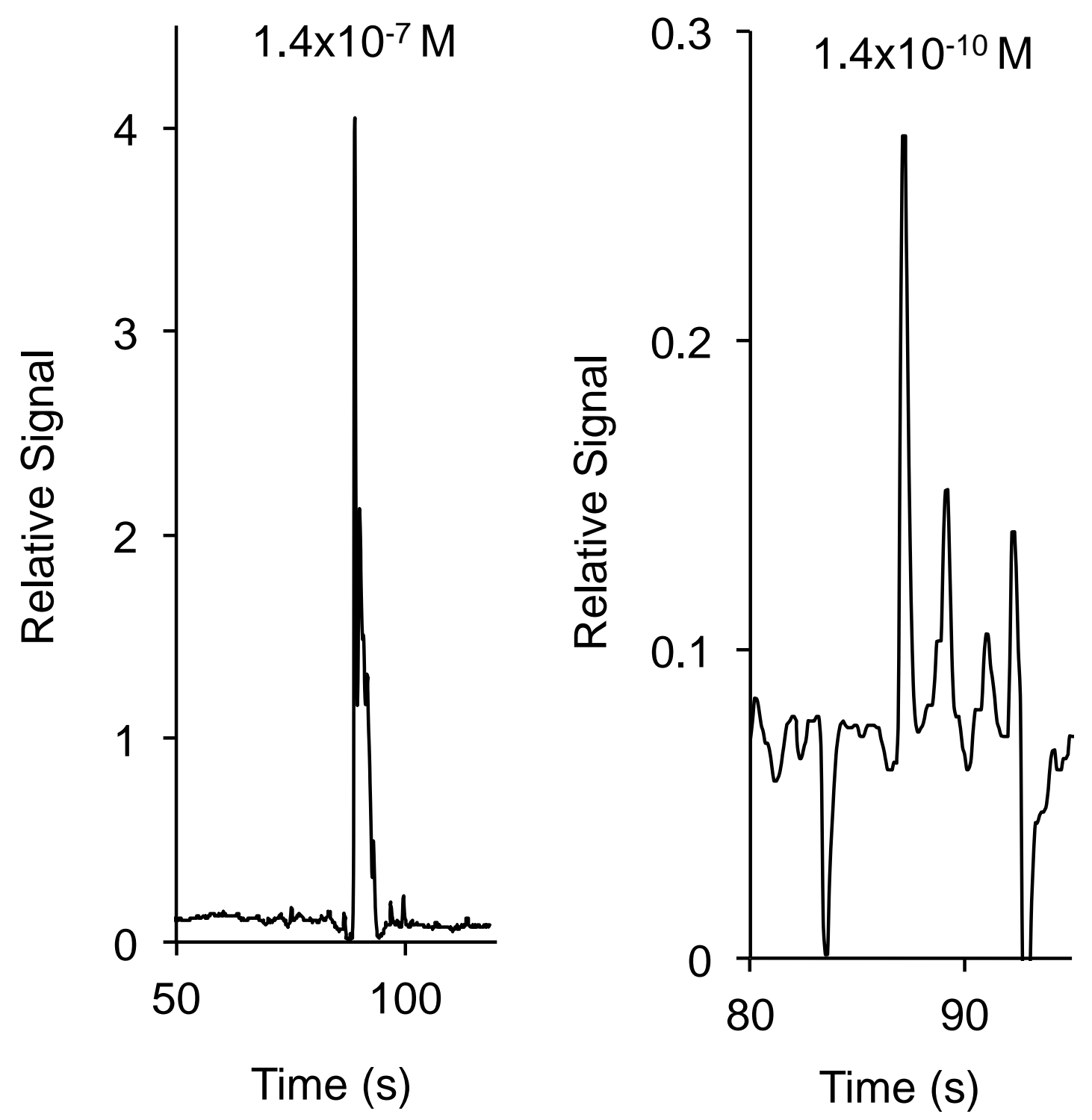

Fig. 8. Electropherograms of QSY 35-conjugated $\alpha$-synuclein $\left(1.4 \times 10^{-7}\right.$, and 1.4 $\left.\times 10^{-10} \mathrm{M}\right)$. Capillary is rinsed with $\mathrm{NaOH}(0.1 \mathrm{M})$, water, and UltraTrol for 3 minutes followed by running buffer ( $100 \mathrm{mM}, \mathrm{pH} 8.6$ Tris-CHES). Capillary: $75 \mu \mathrm{m}$ i.d., 30 $\mathrm{cm}$ (15 cm effective length). $18.0 \mathrm{kV}$ is applied for each run (reverse polarity). The sample is injected electrokinetically for $25 \mathrm{~s}$. 


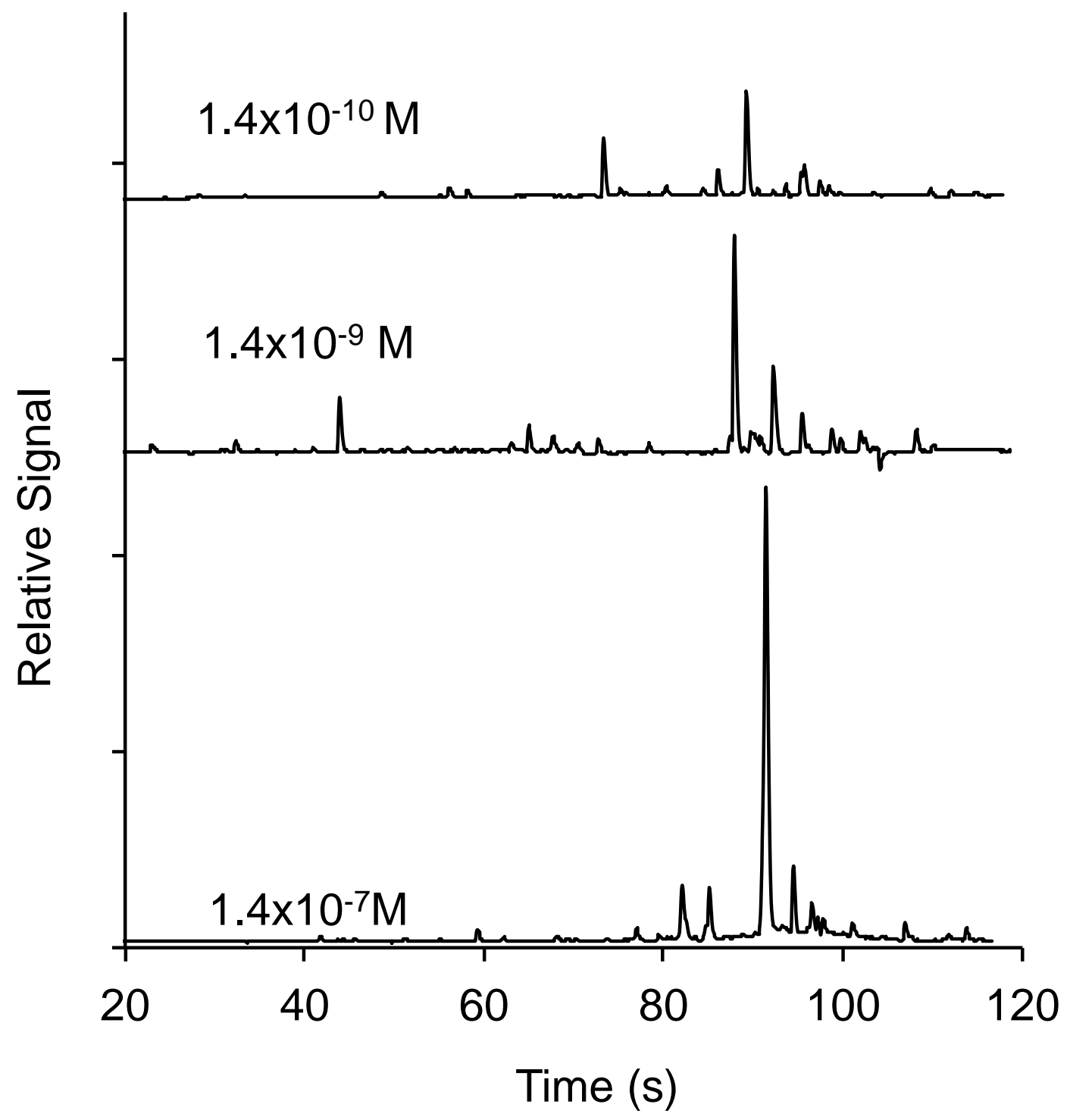

Fig. 9. CE-based laser wave mixing detection limit study for Chromeo P503conjugated $\alpha$-synuclein. Proteins are detected at $1.4 \times 10^{-7} \mathrm{M}, 1.4 \times 10^{-9} \mathrm{M}$, and $1.4 \times 10^{-10} \mathrm{M}$ in $25 \mathrm{mM}$ Tris-CHES buffer (pH 8.6). Capillary is rinsed with $\mathrm{NaOH}$ $(0.1 \mathrm{M})$, water and UltraTrol for 3 minutes followed by background electrolyte (100 $\mathrm{mM}$, pH 8.6 Tris-CHES). Capillary: $75 \mu \mathrm{m}$ i.d., $30 \mathrm{~cm}$ (15 cm effective length). $18.0 \mathrm{kV}$ is applied for each run (reverse polarity). The sample is injected electrokinetically for 20,25 and $25 \mathrm{~s}$.

A protein is a relatively large biomolecule that yields a broad peak as compared to that of a small molecule, and multiple peaks are observed in a 
capillary electrophoresis run. A negatively charged fused-silica capillary wall reacts with multiple charges on protein and causes a high tendency to absorb the protein [36]. To reduce protein-wall interaction in this study, a dynamic coating is applied. The degree of tailing of a peak differs depending on the effectiveness of the wall coating. In addition, there are multiple labeling sites, and individual sites have different reactivity that results in variable labeling and multiple peaks or peak broadening.

By increasing the ratio of Chromeo P503 for the conjugation reaction, the detection limit is improved by three orders of magnitude. Figure 10 shows correlation of reaction ratio and peak height. There are 16 available labeling sites for $\alpha$-synuclein, thus free labels are observed in UV-visible absorption spectra when 20 equivalents of Chromeo P503 are reacted. However, the free label is not observed by CE-based laser wave mixing using a $488 \mathrm{~nm}$ laser since free Chromeo P503 scarcely absorbs at that wavelength, shortening sample preparation time by 5 hours as compared to other labels that require dialysis. Minimizing preparation steps results in cleaner optical background and fewer peaks in the electropherogram. 


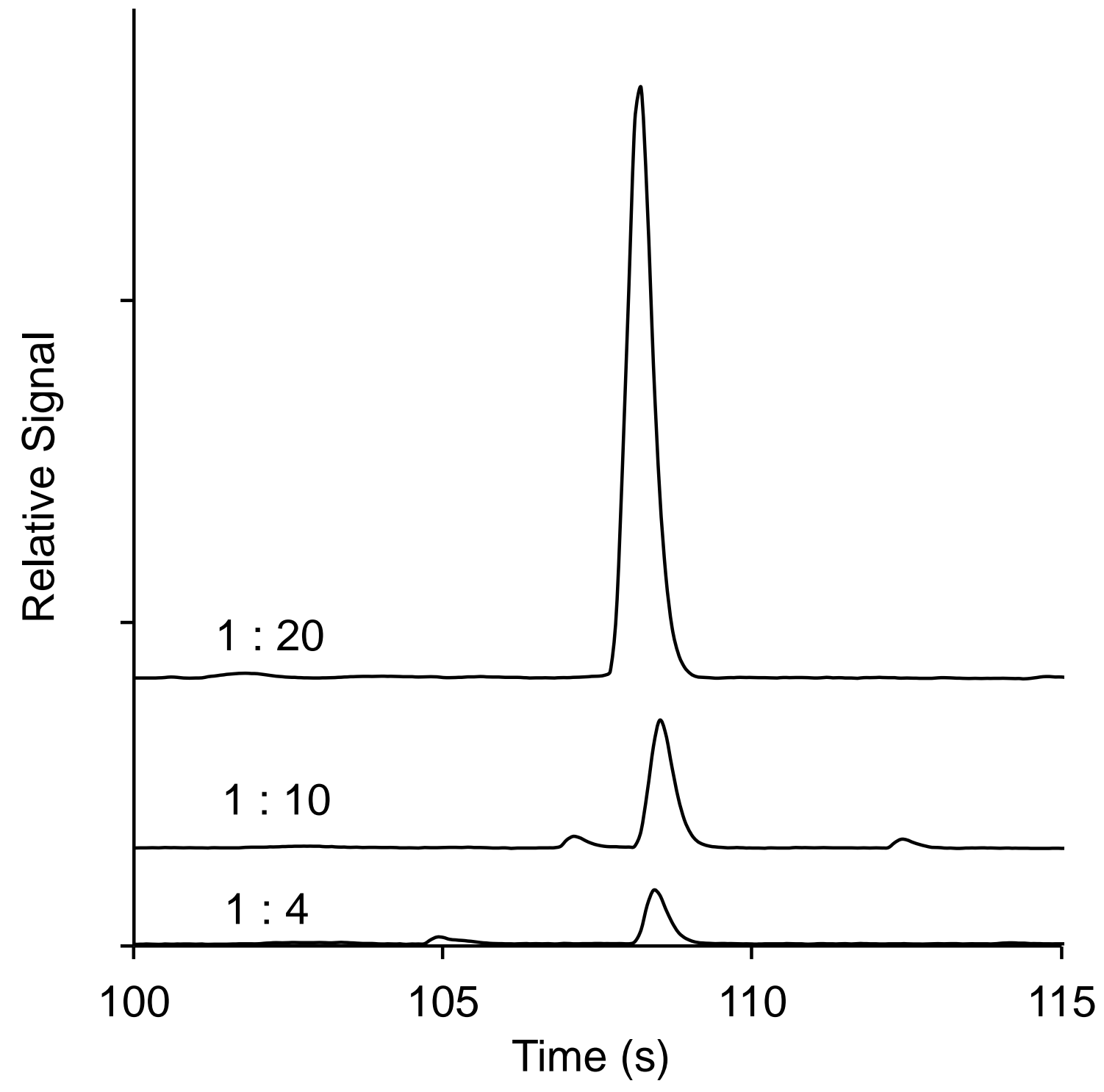

Fig. 10. Electropherograms of Chromeo P503-conjugated $\alpha$-synuclein. Analytes are prepared by using different protein-to-label ratios (1:4, 1:10 and 1:20). Capillary is rinsed with $\mathrm{NaOH}(0.1 \mathrm{M})$, water and UltraTrol for 3 minutes followed by running buffer (100 mM, pH 8.6 Tris-CHES). Capillary: $75 \mu \mathrm{m}$ i.d., $30 \mathrm{~cm}(15$ $\mathrm{cm}$ effective length). $18.1 \mathrm{kV}$ applied to each run (reverse polarity). The sample is injected electrokinetically for $15 \mathrm{~s}$.

When a-synuclein and Chromeo P503 are reacted with a 1:20 ratio, a concentration detection limit of $1.9 \times 10^{-13} \mathrm{M}$ and a mass detection limit of $1.4 \times 10^{-}$ ${ }^{23} \mathrm{~mol}$ are determined. The mass detection limit corresponds to 9 molecules inside 
the probe volume. Figure 11 shows reproducible runs for different concentrations of $\alpha$-synuclein. With optimal protein-label reaction ratio, the detection limit is further enhanced.

Our wave-mixing setup is not a commercial closed system, thus subtle capillary movement, inconsistent temperature, and other outside elements including dust and noise can affect the laser wave mixing CE signal, especially at zepto-mole levels. Noise levels can vary depending on the position of the capillary. To minimize this noise, the capillary is moved horizontally to find the optimal position, which can lead to a migration time shift for CE runs. After multiple runs, two input beams may shift, resulting in a decrease in signal intensity. Since a cooling system is not used for the cappilary, inconsistent temperature levels can also affect migration times. The capillary is mounted on a $X Y Z$ translational stage and adjusted as needed to maximize the $S / N$. 

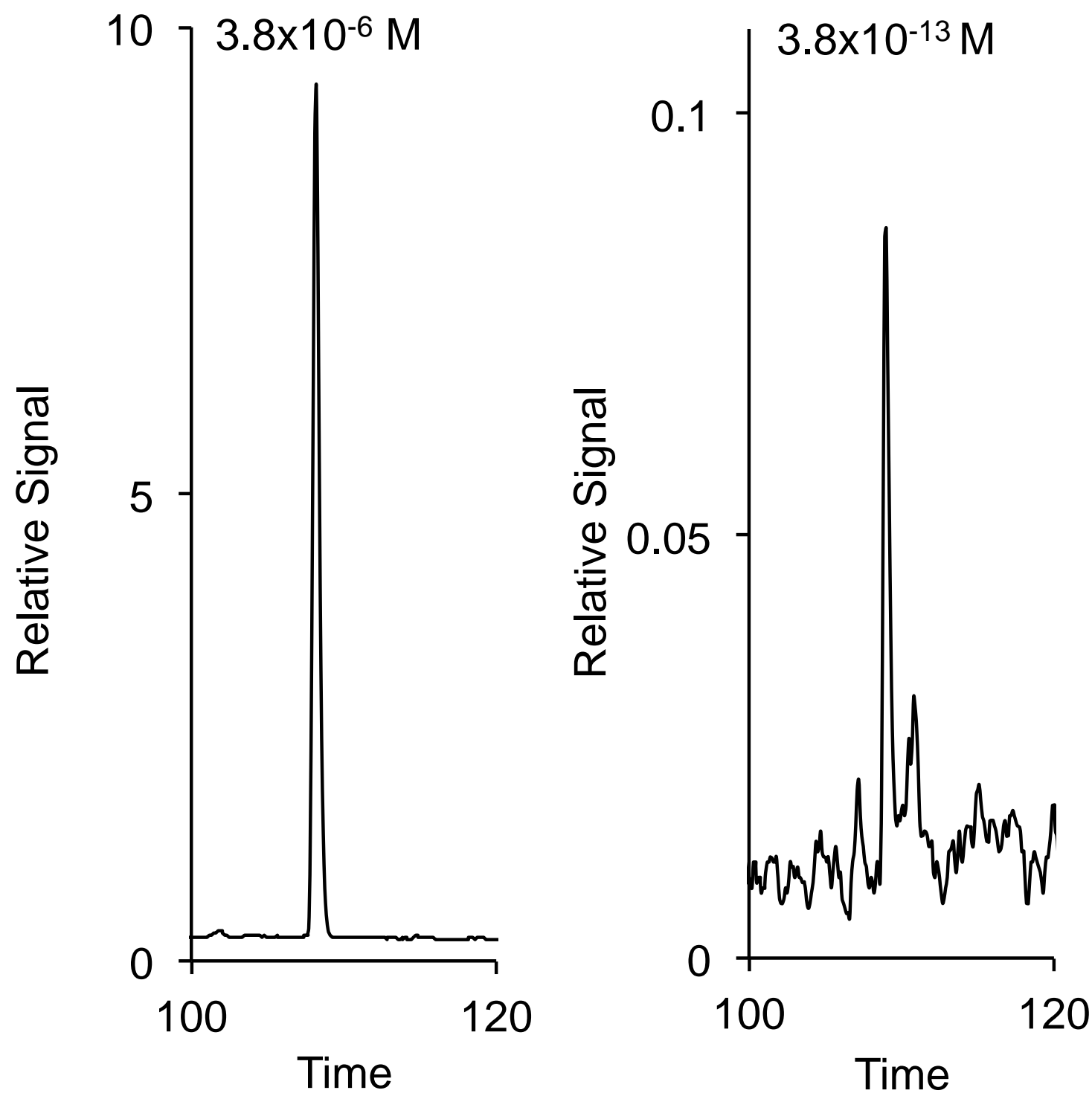

Fig. 11. Electropherograms of un-dialyzed Chromeo P503-conjugated $\alpha$-synuclein (1:20 reaction). Concentrations of the protein are $3.8 \times 10^{-6} \mathrm{M}$ and $3.8 \times 10^{-13} \mathrm{M}$ in $25 \mathrm{mM}$ Tris-CHES buffer $(\mathrm{pH}$ 8.6). The capillary is rinsed with $\mathrm{NaOH}(0.1 \mathrm{M})$, water and UltraTrol for 3 minutes followed by running buffer $(100 \mathrm{mM}, \mathrm{pH}$ 8.6 TrisCHES). Capillary: $75 \mu \mathrm{m}$ i.d., $30 \mathrm{~cm}$ (15 cm effective length). $18.0 \mathrm{kV}$ is applied for each run (reverse polarity). The sample is injected electrokinetically for 15 and $25 \mathrm{~s}$. 
Table 1: Extinction coefficient and detection limit of labels and label-conjugated proteins.

\begin{tabular}{|c|c|c|c|c|c|}
\hline Label & $\begin{array}{c}\text { Highest } \\
\text { Extinction } \\
\text { Coefficient } \\
\left(\mathrm{M}^{-1} \mathrm{~cm}^{-1}\right)\end{array}$ & $\begin{array}{c}\text { Extinction } \\
\text { Coefficient at } \\
488 \mathrm{~nm} \text { with } \\
\text { a-Synuclein } \\
\left(\mathrm{M}^{-1} \mathrm{~cm}^{-1}\right)\end{array}$ & $\begin{array}{c}\text { Detection } \\
\text { Limit } \\
(\mathrm{M})\end{array}$ & $\begin{array}{c}\text { Mass } \\
\text { Detection } \\
\text { Limit (mol) }\end{array}$ & $\begin{array}{c}\text { Number } \\
\text { of } \\
\text { Molecule }\end{array}$ \\
\hline FITC & 70,000 & 231,000 & $1.4 \times 10^{-13}$ & $1.1 \times 10^{-23}$ & 7 \\
\hline QSY 35 & 23,000 & 78,600 & $1.4 \times 10^{-10}$ & $1.1 \times 10^{-20}$ & 6624 \\
\hline $\begin{array}{c}\text { Chromeo } \\
\text { P503 1:4 }\end{array}$ & 24,000 & 78,000 & $1.4 \times 10^{-10}$ & $1.1 \times 10^{-20}$ & 6624 \\
\hline $\begin{array}{c}\text { Chromeo } \\
\text { P503 1:10 }\end{array}$ & 24,000 & 133,000 & $1.9 \times 10^{-13}$ & $1.5 \times 10^{-23}$ & 9 \\
\hline
\end{tabular}

\subsection{Quantitative Measurement of $\alpha$-Synuclein}

Although laser wave mixing yields strong signals, quantitative measurement of $\alpha$-synuclein is challenging due to the reasons mentioned in the previous section. Figure 12 shows electropherograms of FITC-conjugated $\alpha$-synuclein detected by laser wave-mixing interfaced with CGE. The capillary is filled with $3 \%$ PEG and powered by $15 \mathrm{kV}$ to obtain molecular weight-based separation. The laser wavemixing signal has a quadratic dependence on analyte concentration, and hence, it allows more reliable monitoring of small changes in analyte concentration. Figure 13 shows correlations between peak heights and concentrations and a quadratic dependence. The protein is detected at the following concentration levels: 28,56 , 84, 112 and $140 \mu \mathrm{M}$. Peak heights and areas are measured using Origin 8.5. Peak area vs. concentration plot also shows a nearly quadratic dependence (slope of 1.87). The slope is not exactly 2.0 (theoretical value) for peak heights and peak areas due to some background noise and exterior influences. 
Laser wave mixing, interfaced to $\mathrm{CE}$, offers high $\mathrm{S} / \mathrm{N}$ and yields reproducible CE runs, while ELISA struggles with background control absorption and crossreactivity interferences that result in false results. Moreover, CE-based laser wave mixing is much faster than ELISA and SDS-PAGE. Thus, this nonlinear absorption-based wave-mixing detection method is promising for fast and reliable analyses of clinical samples. 


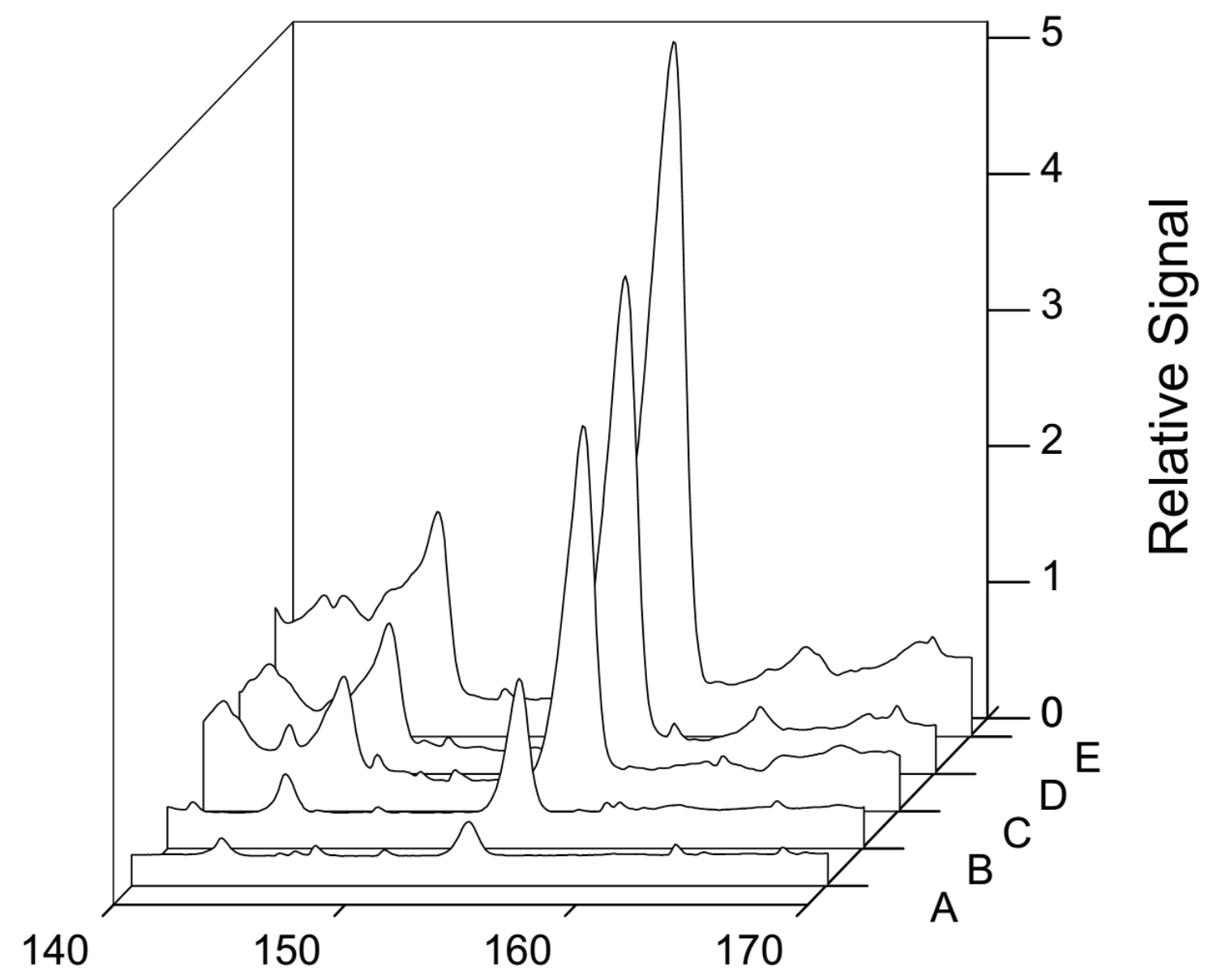

Fig. 12. Electropherograms for FITC-conjugated $\alpha$-synuclein. Proteins are detected at different concentrations: (A) $28 \mu \mathrm{M}$, (B) $56 \mu \mathrm{M}$, (C) $84 \mu \mathrm{M}$, (D) $112 \mu \mathrm{M}$, and $(\mathrm{E}) 140 \mu \mathrm{M}$ in $25 \mathrm{mM}$ Tris-CHES buffer (pH 8.6). Capillary is rinsed with $\mathrm{NaOH}$ $(0.1 \mathrm{M})$, water and UltraTrol, and running buffer (3\% PEG, $100 \mathrm{mM}$ Tris-CHES, and $0.1 \%$ SDS) for 3 minutes. Capillary: $75 \mu \mathrm{m}$ i.d., $30 \mathrm{~cm}$ (15 $\mathrm{cm}$ effective length). $15.0 \mathrm{kV}$ is applied for each run (reverse polarity). The sample is injected electrokinetically for $5 \mathrm{~s}$ and detected by a $50 \mathrm{~mW} 473 \mathrm{~nm}$ laser. 


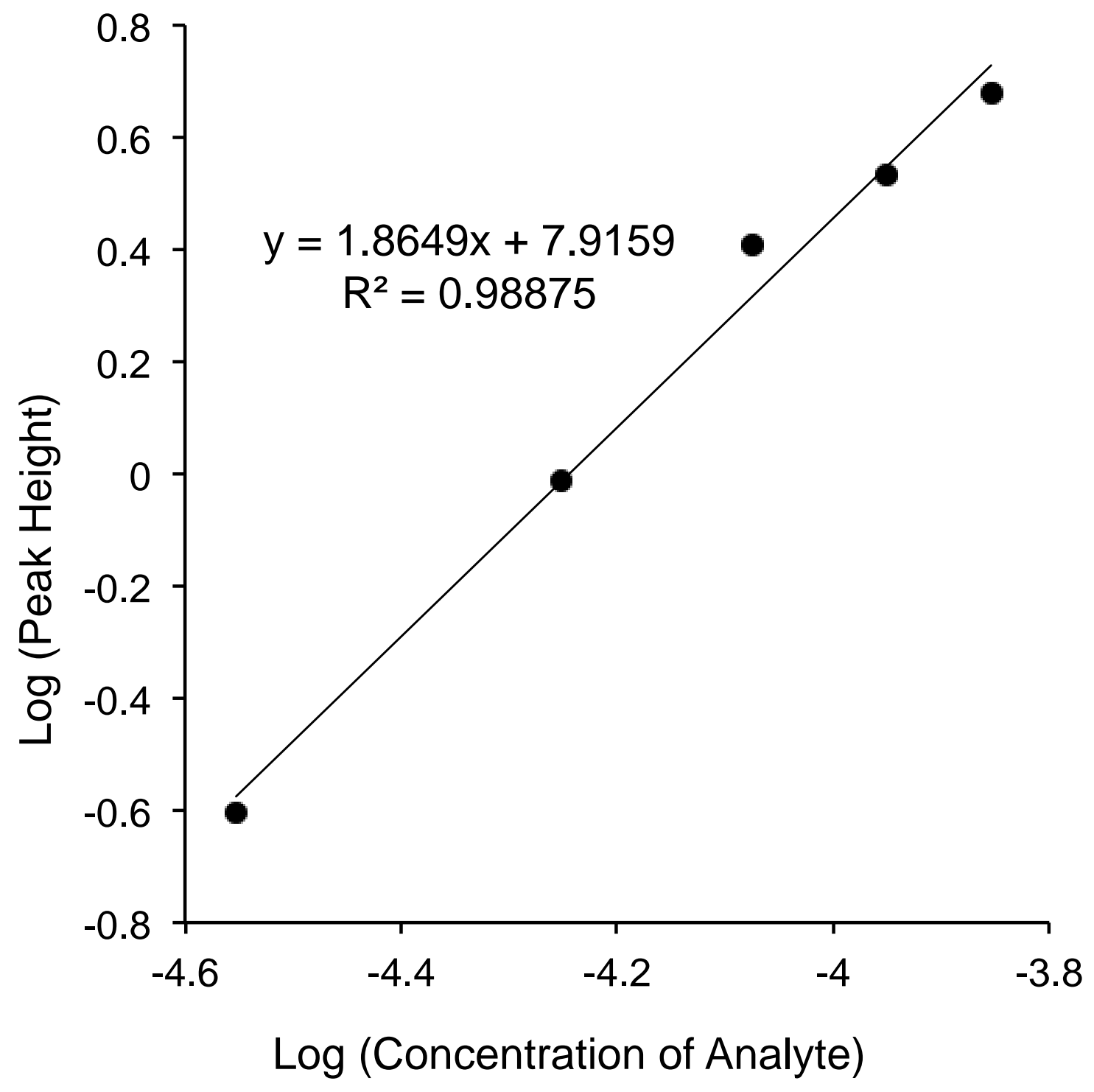

Fig. 13. Quadratic dependence on concentration for FITC-conjugated $\alpha$-synuclein with a slope of 1.87 . 


\section{Conclusion}

Nonlinear absorption-based laser wave mixing provides ultrasensitive detection for FITC, QSY 35 and Chromeo P503-conjugated protein related to Parkinson's disease. FITC and Chromeo P503-conjugated analytes yield the best detection limits. The wave-mixing signal is a coherent laser-like beam that can be collected with excellent efficiency and high signal-to-noise ratios. Laser wave mixing is convenient and faster than SDS-PAGE and ELISA in determining molecular weight of a protein for the purpose of investigating oligomeric forms. While this paper focuses on separation of multi-forms of a-synuclein, other studies show that the aggregation of the protein is accelerated by post-translational modification such as Ser-129 phosphorylation [12]. Laser wave-mixing detection coupled with CE could also separate and detect phosphorylated $\alpha$-synuclein by modifying CE matrix and additives since it can separate peptides with a one-amino-acid difference and even isomers [37]. Potential applications include sensitive, reliable, fast and convenient detection of $\alpha$-synuclein for early diagnosis of Parkinson's using a few drops of blood sample.

\section{Acknowledgments}

We gratefully acknowledge partial support of this work from the National Institute of General Medical Sciences, National Institutes of Health under Grant 5R01-GM41032, the National Science Foundation, the U.S. Department of Homeland Security, the U.S. Department of Defense (CCAT), the ARCS 
Foundation (Manna Iwabuchi and Marcel Hetu), and the NIH NIGMS SDSU IMSD Program grant 2R25GM058906-13. 


\section{Reference}

[1] A. McNeill, R.M. Wu, K.Y. Tzen, P.C. Aguiar, J.M. Arbelo, P. Barone, K. Bhatia, O. Barsottini, V. Bonifati, S. Bostantjopoulou, R. Bressan, G. Cossu, P. Cortelli, A. Felicio, H.B. Ferraz, J. Herrera, H. Houlden, M. Hoexter, C. Isla, A. Lees, O. Lorenzo-Betancor, N.E. Mencacci, P. Pastor, S. Pappata, M.T. Pellecchia, L. Silveria-Moriyama, A. Varrone, T. Foltynie, A.H. Schapira, Dopaminergic neuronal imaging in genetic Parkinson's disease: insights into pathogenesis, PLoS One, 8 (2013) e69190. [2] A. Merola, M. Zibetti, S. Angrisano, L. Rizzi, V. Ricchi, C.A. Artusi, M. Lanotte, M.G. Rizzone, L. Lopiano, Parkinson's disease progression at 30 years: a study of subthalamic deep brain-stimulated patients, Brain, 134 (2011) 2074-2084. [3] R. Savica, W.A. Rocca, J.E. Ahlskog, When Does Parkinson Disease Start?, Arch Neurol-Chicago, 67 (2010) 798-801.

[4] M. Baba, S. Nakajo, P.H. Tu, T. Tomita, K. Nakaya, V.M.Y. Lee, J.Q. Trojanowski, T. Iwatsubo, Aggregation of alpha-synuclein in Lewy bodies of sporadic Parkinson's disease and dementia with lewy bodies, Am J Pathol, 152 (1998) 879-884. [5] J.C. Lee, R. Langen, P.A. Hummel, H.B. Gray, J.R. Winkler, Alpha-synuclein structures from fluorescence energy-transfer kinetics: implications for the role of the protein in Parkinson's disease, Proceedings of the National Academy of Sciences of the United States of America, 101 (2004) 16466-16471.

[6] M.J. Roberti, C.W. Bertoncini, R. Klement, E.A. Jares-Erijman, T.M. Jovin, Fluorescence imaging of amyloid formation in living cells by a functional, tetracysteine-tagged alpha-synuclein, Nat Methods, 4 (2007) 345-351.

[7] B.K. Choi, M.G. Choi, J.Y. Kim, Y. Yang, Y. Lai, D.H. Kweon, N.K. Lee, Y.K. Shin, Large alpha-synuclein oligomers inhibit neuronal SNARE-mediated vesicle docking, Proceedings of the National Academy of Sciences of the United States of America, 110 (2013) 4087-4092.

[8] S. Goncalves, T.F. Outeiro, Assessing the subcellular dynamics of alpha-synuclein using photoactivation microscopy, Molecular neurobiology, 47 (2013) 1081-1092. [9] a.M.F.B. Bobby Thomas, Molecular insights into Parkinson's disease, F1000 Medicine Reports, 3 (2011).

[10] V.M. Lee, J.Q. Trojanowski, Mechanisms of Parkinson's disease linked to pathological alpha-synuclein: new targets for drug discovery, Neuron, 52 (2006) 3338.

[11] L.V. Kalia, S.K. Kalia, P.J. McLean, A.M. Lozano, A.E. Lang, alpha-Synuclein oligomers and clinical implications for Parkinson disease, Ann Neurol, 73 (2013) 155-169.

[12] B. Thomas, Parkinson's disease: from molecular pathways in disease to therapeutic approaches, Antioxidants \& redox signaling, 11 (2009) 2077-2082. [13] M. Bucciantini, E. Giannoni, F. Chiti, F. Baroni, L. Formigli, J. Zurdo, N. Taddei, G. Ramponi, C.M. Dobson, M. Stefani, Inherent toxicity of aggregates implies a common mechanism for protein misfolding diseases, Nature, 416 (2002) 507-511.

[14] J. Lotharius, P. Brundin, Pathogenesis of Parkinson's disease: dopamine, vesicles and alpha-synuclein, Nature reviews. Neuroscience, 3 (2002) 932-942. 
[15] E. Hirsch, A.M. Graybiel, Y.A. Agid, Melanized dopaminergic neurons are differentially susceptible to degeneration in Parkinson's disease, Nature, 334 (1988) 345-348.

[16] G.M. Halliday, D.A. McRitchie, H. Cartwright, R. Pamphlett, M.A. Hely, J.G. Morris, Midbrain neuropathology in idiopathic Parkinson's disease and diffuse Lewy body disease, Journal of clinical neuroscience : official journal of the Neurosurgical Society of Australasia, 3 (1996) 52-60.

[17] J.M. Fearnley, A.J. Lees, Ageing and Parkinson's disease: substantia nigra regional selectivity, Brain, 114 ( Pt 5) (1991) 2283-2301.

[18] K.A. Conway, J.C. Rochet, R.M. Bieganski, P.T. Lansbury, Jr., Kinetic stabilization of the alpha-synuclein protofibril by a dopamine-alpha-synuclein adduct, Science, 294 (2001) 1346-1349.

[19] J. Burre, M. Sharma, T. Tsetsenis, V. Buchman, M.R. Etherton, T.C. Sudhof, Alphasynuclein promotes SNARE-complex assembly in vivo and in vitro, Science, 329 (2010) 1663-1667.

[20] M.N. Kensaku Kasuga, Takeshi Ikeuchi, $\alpha$-Synuclein as CSF and Blood Biomarker of Dementia with Lewy Bodies, International Journal of Alzheimer's Disease, (2012) 1-9.

[21] T. Tokuda, S.A. Salem, D. Allsop, T. Mizuno, M. Nakagawa, M.M. Qureshi, J.J. Locascio, M.G. Schlossmacher, O.M. El-Agnaf, Decreased alpha-synuclein in cerebrospinal fluid of aged individuals and subjects with Parkinson's disease, Biochem Biophys Res Commun, 349 (2006) 162-166.

[22] B. Mollenhauer, V. Cullen, I. Kahn, B. Krastins, T.F. Outeiro, I. Pepivani, J. Ng, W. Schulz-Schaeffer, H.A. Kretzschmar, P.J. McLean, C. Trenkwalder, D.A. Sarracino, J.P. Vonsattel, J.J. Locascio, O.M. El-Agnaf, M.G. Schlossmacher, Direct quantification of CSF alpha-synuclein by ELISA and first cross-sectional study in patients with neurodegeneration, Exp Neurol, 213 (2008) 315-325.

[23] D.C. L. Parnetti, G. Bellomo et al., Cerebrospinal fluid Tau/ $\alpha$-synuclein ratio in Parkinson's disease and degenerative dementias, Movement Disorders, 26 (2011) 1428-1435.

[24] P.H. Lee, G. Lee, H.J. Park, O.Y. Bang, I.S. Joo, K. Huh, The plasma alpha-synuclein levels in patients with Parkinson's disease and multiple system atrophy, J Neural Transm, 113 (2006) 1435-1439.

[25] R. Duran, F.J. Barrero, B. Morales, J.D. Luna, M. Ramirez, F. Vives, Plasma $\alpha$ synuclein in patients with Parkinson's disease with and without treatment, Movement Disorders, 25 (2010) 489-493.

[26] M. Shi, C.P. Zabetian, A.M. Hancock, C. Ginghina, Z. Hong, D. Yearout, K.A. Chung, J.F. Quinn, E.R. Peskind, D. Galasko, J. Jankovic, J.B. Leverenz, J. Zhang, Significance and confounders of peripheral DJ-1 and alpha-synuclein in Parkinson's disease, Neurosci Lett, 480 (2010) 78-82.

[27] N.A. Guzman, T. Blanc, T.M. Phillips, Immunoaffinity capillary electrophoresis as a powerful strategy for the quantification of low-abundance biomarkers, drugs, and metabolites in biological matrices, Electrophoresis, 29 (2008) 3259-3278. [28] J.A. Nunes, W.G. Tong, Sensitive circular dichroism spectroscopy based on nonlinear degenerate four-wave mixing, Anal Chem, 65 (1993) 2990-2994. 
[29] C. Prata, P. Bonnafous, N. Fraysse, M. Treilhou, V. Poinsot, F. Couderc, Recent advances in amino acid analysis by capillary electrophoresis, Electrophoresis, 22 (2001) 4129-4138.

[30] V. García-Cañas, A. Cifuentes, Recent advances in the application of capillary electromigration methods for food analysis, Electrophoresis, 29 (2008) 294-309. [31] C.T. Liu, L. Wang, N.M. Goodey, P. Hanoian, S.J. Benkovic, Temporally overlapped but uncoupled motions in dihydrofolate reductase catalysis, Biochemistry-Us, 52 (2013) 5332-5334. [32] E.H. Turner, J.A. Dickerson, L.M. Ramsay, K.E. Swearingen, R. Wojcik, N.J. Dovichi, Reaction of fluorogenic reagents with proteins III. Spectroscopic and electrophoretic behavior of proteins labeled with Chromeo P503, J Chromatogr A, 1194 (2008) 253-256.

[33] D.B. Craig, B.K. Wetzl, A. Duerkop, O.S. Wolfbeis, Determination of picomolar concentrations of proteins using novel amino reactive chameleon labels and capillary electrophoresis laser-induced fluorescence detection, Electrophoresis, 26 (2005) 2208-2213.

[34] S. de Jong, S.N. Krylov, Protein labeling enhances aptamer selection by methods of kinetic capillary electrophoresis, Anal Chem, 83 (2011) 6330-6335.

[35] J.G.C. Tim Bartels, and Dennis J. Selkoe, alpha-Synuclein occurs physiologically as a helically folded tetramer that resists aggregation, Nature, 477 (2011) 107-110. [36] K. Shariff, S. Ghosal, Peak tailing in electrophoresis due to alteration of the wall charge by adsorbed analytes a Numerical simulations and asymptotic theory, Analytica Chimica Acta, 507 (2004) 87-93.

[37] R. Verpillot, H. Esselmann, M.R. Mohamadi, H. Klafki, F. Poirier, S. Lehnert, M. Otto, J. Wiltfang, J.L. Viovy, M. Taverna, Analysis of Amyloid-beta Peptides in Cerebrospinal Fluid Samples by Capillary Electrophoresis Coupled with LIF Detection, Anal Chem, 83 (2011) 1696-1703. 